University of New Mexico

UNM Digital Repository

Mathematics and Statistics Faculty and Staff

Publications

Academic Department Resources

$10-2020$

Decision Making on Teachers' adaptation to Cybergogy in

Saturated Interval- valued Refined Neutrosophic overset /underset

/offset Environment

Florentin Smarandache

Nivetha Martin

Priya R.

Follow this and additional works at: https://digitalrepository.unm.edu/math_fsp

Part of the Adult and Continuing Education Commons, Educational Technology Commons, Logic and Foundations Commons, Number Theory Commons, and the Other Mathematics Commons 


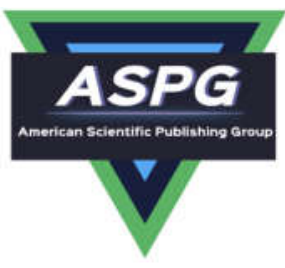

\title{
Decision Making on Teachers' adaptation to Cybergogy in Saturated Interval- valued Refined Neutrosophic overset/underset /offset Environment
}

\author{
Nivetha Martin ${ }^{1}$, Priya $\mathbf{R}^{2}$ and Florentin Smarandache ${ }^{3}$ \\ ${ }^{1}$ Department of Mathematics, Arul Anandar College (Autonomous), Karmathur, India, \\ nivetha.martin710@gmail.com \\ ${ }^{2}$ Department of Mathematics, PKN Arts and Science College, Thirumangalam, India, \\ iampriyaravi@gmail.com \\ ${ }^{3}$ Department of Mathematics, University of New Mexico, Gallup, NM 87301, USA, \\ smarand@unm.edu
}

\begin{abstract}
Neutrosophic overset, neutrosophic underset and neutrosophic offset introduced by Smarandache are the special kinds of neutrosophic sets with values beyond the range $[0,1]$ and these sets are pragmatic in nature as it represents the real life situations. This paper introduces the concept of saturated refined neutrosophic sets and extends the same to the special kinds of neutrosophic sets. The proposed concept is applied in decision making on Teacher's adaptation to cybergogy. The decision making environment is characterized by different types of teachers, online teaching skills and various training methods. Fuzzy relation is used to match the most suitable method to the different kinds of teachers with the intervention of saturated interval valued neutrosophic refined oversets, offsets and undersets. The results obtained by applying the notion of saturated refined sets using various distance measures represent the effect of training methods on teacher's adaptation to learner-centred teaching methods, which certainly give space to gain many insights on the relationship between quality of training and teacher's adaptation rate. The proposed concept has wide scope and few limitations.
\end{abstract}

Keywords: neutrosophic oversets, neutrosophic offsets, neutrosophic offsets, refined sets, saturated, interval-valued sets, cybergogy

\section{Introduction}

Decision making is an indispensable activity but the environment is highly characterized with uncertainty. The concept of fuzzy set introduced by Lofti.A.Zadeh [1] plays a vital role in tackling such uncertain and imprecise situations. 
Fuzzy sets differ from crisp sets by membership functions and membership values. The elements of crisp sets contain binary membership values i.e either 1 or 0 , it doesn't deal with intermediate values. Fuzzy sets overcome this short coming with the inclusion of intermediate values and extending the range of values from $\{0,1\}$ to $[0,1]$. Fuzzy sets are highly comprehensive and inclusive in nature. Fuzzy sets are extensively used to handle complex systems and control as these sets possess high rate of industrial applications. Fuzzy sets are extended to intuitionistic sets by Atanssov[2] with the introduction of non-membership function to membership function. The elements of intuitionistic sets possess both membership and non-membership values ranging from $[0,1]$. The hesitancy margin is calculated by subtracting the sum of membership and non-membership values from 1. In intuitionistic sets the hesitancy margin is dependent on membership and non-membership values. Intuitionistic sets and various forms of it are widely used in multiple attribute decision making. Khan et al [3] used Interval-valued Pythagorean fuzzy GRA method for multiple-attribute decision making with incomplete weight information. Zhuosheng Jia et al[4] used interval valued intuitionistic fuzzy sets in multiple attribute group decision making method TOPSIS. Intuitionistic sets are further extended to neutrosophic sets by Smarandache[5] and these sets have truth membership functions, indeterminacy functions and non-membership functions. The elements of neutrosophic sets are triplets with independent truth, indeterminacy and false membership values ranging from $[0,1]$. Neutrosophic sets are widely used in multiple attribute decision making. Abdel-Baset et al $[6,7]$ developed multi criteria decision making method with neutrosophic representation in evaluating green supply chain management practices and in sustainable supplier selection. Hu et al [8] also contributed to neutrosophic decision making on the selection of doctors.Nada A. Nabeeh et al [9] proposed a hybrid approach of neutrosophic with MULTIMOORA in application of personnel selection. Ajay et al [10] developed the single -valued triangular neutrosophic approach of decision making on multi objectives based on ratio analysis.Sahidul Islam et al [11] formulated neutrosophic goal programming approach to a green supplier selection model with quantity discount. Mullai.M et al [12] used neutrosophic intelligent energy efficient routing for wireless ad-hoc network based on multicriteria decision making. Abdel Nasser et al [13] proposed an integrated neutrosophic and TOPSIS for evaluating airline service quality. Neutrosophic hypersoft sets are also used in decision making. Muhammad Saqlain et al [14] presented the applications of neutrosophic hypersoft sets in TOPSIS using accuracy function. Surapati et al[15] developed Multi-level linear programming problem with neutrosophic numbers. Ajay et al [16,17] discussed decision making techniques based on bipolar neutrosophic sets, neutrosophic cubic fuzy sets, Chakravarthy et al $[18,19]$ expounded the implications of cyclindrical and pentagonal neutrosophic numbers in networking and mobile communication respectively . Deli et al $[20,21]$ proposed multi attribute decision making models based on weighted geometric operators and two centroid point for single valued triangular neutrosophic number. Neutrosophic graphs are also widely used in decision making. Juanjuan et al [22] developed a multi attribute decision making model using single valued neutrosophic graphs. Dragisa et al [23] proposed a novel approach of assessing the reliability of the data in decision making. Shahzaib et al [24] framed a decision making model to select agroculture land using neutrosophic information. Muhammad et al [25] developed auto car decision making model using Bipolar Neutrosophic Soft Sets. Philippe [26] has also discussed the neutrosophical representations in cognitive dimension. The neutrosophic sets are extensively applied in multi criteria decision making.

Smarandache [27] introduced neutrosophic oversets, offsets and undersets which are the special kinds of neutrosophic sets with values beyond [0,1]. Overset is characterized with membership values greater than 1 , underset is characterized with membership values less than 0 and the combination of both these sets is offset. Smarandache justified the practical implications of these special kinds of sets with real life illustrations. These kinds of neutrosophic sets highly influenced and motivated us to propose a fuzzy relational decision making model with saturated refined interval- valued neutrosophic oversets, undersets and offsets based on application of refined neutrosophic sets in medical diagnosis by Deli et al [28]. Smarandache conceptualized n-valued refined neutrosophic sets and these sets are used in decision making model of medical diagnosis. Broumi [29] extended the model of Deli et al by applying correlation measure. Various distance measures are used to make optimal decisions without changing the neutrosophic representations. In their model relation between symptoms and diseases was represented by neutrosophic sets; relation between patients and symptoms was represented by refined neutrosophic sets over certain interval period of time. In this decision making model the representation of the symptoms of the patients varies from time to time. But on 
profound analysis, the effects of treatment on the status and the degree of symptoms lack representation. This deficit in the decision maing model paved the way for developing a novel decision making model with new kind of representations. The same model is extended to fuzzy relation decision making model on teacher's adaptation to cybergogy in this research work. A relation between digital teaching skills and training methods is represented by neutrosophic sets and the relation between different kinds of teachers and the acquisition of digital skills after continuous stages of training is represented by refined neutrosophic oversets, undersets and offsets. Such kinds of representations are made to reflect the impact of training on skill acquisition rate by the teachers. The degree of digital skill acquisition by the teacher greatly depends on the personal interest, trainer's approach and training environment. The self- interest of the teachers may induce them to spend additional time other than the specified training time; also the disinterest of the teachers or dislike of trainer's approach may make them to refrain from the training and their participation rate is disturbed. At such circumstances refined neutrosophic oversets, underset and offset are used to represent such impacts. Also a new concept of saturated refined sets is introduced in this paper. The refined neutrosophic overset, underset and offset values remain to settle to a particular value over a consecutive period of time then it is called as saturated. The existences of situations where the degree of digital skill acquisition is confined and attained the maximum value and also there is no chance of further change over a period of training can be represented by saturated refined neutrosophic sets. The apt method of training to different kinds of teachers is determined by using hamming distance, normalized hamming distance, Euclidean distance and normalized Euclidean distance measures. The practical implications of neutrosophic overset, underset and offset are not explored to the best of the knowledge and so this research work will certainly fill the gap and it is intended to do so.

The paper is organized as follows: section 2 presents the basic definitions; section 3 describes about saturated refined neutrosophic sets; section 4 consists of the application of the proposed model; section 5 discusses the results and the last section concludes the work.

\section{Preliminaries}

\section{Definition 2.1 [27]}

Let $\mathrm{X}$ be an universe of discourse, $\mathrm{A}$ neutrosophic set $\mathrm{A}$ in $\mathrm{X}$ is expressed by $\mathrm{A}=\left\{<X ; T_{A}(x), I_{A}(x), F_{A}(x)>/ x \in\right.$ $X$ \} and T,I,F:X $\rightarrow]^{-0} 0: 1^{+}[$where T,I,F are the degree of membership(True), the indeterminacy and degree of nonmembership(False) respectively, and $0 \leq T_{A}(x)+I_{A}(x)+F_{A}(x) \leq 3$.

\section{Definition 2.2 [27]}

Let $\mathrm{X}$ be the universe of discourse with a generic element in $\mathrm{X}$ is denoted by $\mathrm{x}$. An interval valued neutrosophic set (IVNS) $\mathrm{A}$ in $\mathrm{X}$ is defined by $\mathrm{A}=\left\{x,<\left[T_{A}^{L}(x), T_{A}^{U}(x)\right],\left[I_{A}^{L}(x), I_{A}^{U}(x)\right],\left[F_{A}^{L}(x), F_{A}^{U}(x)\right]>; x \in X\right\}$

where $T_{A}, I_{A}, F_{A}$ are the truth membership function, indeterminacy membership function, falsity membership function respectively.For each point $\mathrm{x}$ in $\mathrm{X}$, We have $\left[T_{A}^{L}(x), T_{A}^{U}(x)\right],\left[I_{A}^{L}(x), I_{A}^{U}(x)\right],\left[F_{A}^{L}(x), F_{A}^{U}(x)\right] \subseteq[0,1]$ with the condition $0 \leq T_{A}^{U}(x)+I_{A}^{U}(x)+F_{A}^{U}(x) \leq 3$.

\section{Definition2.3 [27]}

Let $U$ be a universe of discourse. A neutrosophic refined set (NRS) A on U can be defined as follows

$$
\mathrm{A}=\left\{<\mathrm{x},<\mathrm{T}_{A}^{1}(x), T_{A}^{2}(x) \ldots T_{A}^{P}(x)\right),\left(I_{A}^{1}(x), I_{A}^{2}(x) \ldots I_{A}^{P}(x)\right),\left(F_{A}^{1}(x) F_{A}^{2}(x) \ldots F_{A}^{P}(x)>x \in U\right\} \text { and }
$$

$0 \leq T_{A}^{i}(x)+I_{A}^{i}(x)+F_{A}^{i}(x) \leq 3,(i=1,2 \ldots P) \operatorname{and} T_{A}^{1}(x) \leq T_{A}^{2}(x) \leq \cdots \leq \mathbb{T}_{A}^{P}(x)$ for any

$x \in A, T_{A}^{i}(x), I_{A}^{i}(x), F_{A}^{i}(x), i=1,2 \ldots$ Ps the truth membership sequence, indeterminancy membership sequence and falsity membership sequence of the element $\mathrm{x}$ respectively. 


\section{Definition 2.4 [27]}

Let $U$ be the universe of discourse. A neutrosophic set $A_{1}$ in $U$ which consist the membership function $\mathrm{T}(\mathrm{x}), \mathrm{I}(\mathrm{x}), \mathrm{F}(\mathrm{x})$ that define true, Indeterminacy and falsity respectively, of a generic element $\mathrm{x} \in U$, $T_{A}(x), I_{A}(x), F_{A}(x): U \rightarrow[0, \varphi]$ w here $0<1<\varphi$, and $\varphi$ is called over limit.

A single valued neutrosophic over set $\mathrm{A}_{1}$ is defined as

$\mathrm{A}_{1}=\left\{\mathrm{x},<T_{A}(x) ; I_{A}(x) ; F_{A}(x)>\mathrm{x} \in U\right\}$ such that in the neutrosophic components contains there exist atleast one element in $A_{1}$ is $>1$ and no element is $<0$.

\section{Definition 2.5[27]}

Let $U$ be the universe of discourse. A neutrosophic set $A_{2}$ in $U$ which consist the membership function $T(x), I(x)$, $\mathrm{F}(\mathrm{x})$ that define true, Indeterminacy and falsity respectively, of a generic element $\mathrm{x} \in U$,

$$
T_{A}(x), I_{A}(x), F_{A}(x): U \rightarrow[\psi, 1] \text { where } \psi<0<1 \text {, and } \psi \text { is called under limit. }
$$

A single valued neutrosophic underset $\mathrm{A}_{2}$ is defined as

$$
\mathrm{A}_{2}=\left\{\mathrm{x},<\mathrm{T}_{A}(x) ; I_{A}(x) ; F_{A}(x)>\mathrm{x} \in U\right\}
$$

such that in the neutrosophic components contains there exist atleast one element in $\mathrm{A}_{2}$ is $<0$ and no element is $>1$

\section{Definition 2.6 [27]}

Let $\mathrm{U}$ be the universe of discourse. A neutrosophic set $\mathrm{A}_{3}$ in $\mathrm{U}$ which consist the membership function $\mathrm{T}(\mathrm{x}), \mathrm{I}(\mathrm{x}), \mathrm{F}(\mathrm{x})$ that define true, Indeterminacy and falsity respectively, of a generic element $\mathrm{x} \in U$,

$$
T_{A}(x), I_{A}(x), F_{A}(x): U \rightarrow[\psi, \varphi] w \text { here } \psi<0<1<\varphi \text {, and } \psi \text { is called under limit while } \varphi \text { is called over }
$$

limit, $T_{A}(x), I_{A}(x), F_{A}(x) \in[\psi, \varphi]$.The neutrosophic single-valued offset $\mathrm{A}_{3}$ is defined by

$\mathrm{A}_{3}=\left\{\mathrm{x},<\mathrm{T}_{A}(x) ; I_{A}(x) ; F_{A}(x)>\mathrm{x} \in U\right\}$ such that in the neutrosophic components contains there is atleast one element is $>1$ and atleast another is $<0$.

\section{Definition 2.7 [27]}

Let $U$ be the universe of discourse. A neutrosophic set $A_{1}$ in $U$ which consist the membership function $T(x), I(x), F(x)$ that define true, Indeterminacy and falsity respectively, of a generic element $\mathrm{x} \in U$,

$T_{A}(x), I_{A}(x), F_{A}(x): U \rightarrow P([0, \varphi])$ where $0<1<\varphi$, and $\varphi$ is called over limit,

$T_{A}(x), I_{A}(x), F_{A}(x) \subseteq[0, \varphi]$, and $P([0, \varphi])$ is the set of all subsets of $[0, \varphi]$.An interval valued neutrosophic overset $\mathrm{A}_{1}$ is defined as $\mathrm{A}_{1}=\left\{\mathrm{x},<\mathrm{T}_{A}(x) ; I_{A}(x) ; F_{A}(x)>\mathrm{x} \in U\right\}$ such that in the neutrosophic component contains there is atleast one is partially or totally above 1 and no element has partially or totally below 0 .

\section{Definition 2.8 [27]}

Let $\mathrm{U}$ be the universe of discourse. A neutrosophic set $\mathrm{A}_{2}$ in $\mathrm{U}$ which consist the membership function $\mathrm{T}(\mathrm{x}), \mathrm{I}(\mathrm{x}), \mathrm{F}(\mathrm{x})$ that define true, Indeterminacy and falsity respectively, of a generic element $\mathrm{x} \in U$,

$T_{A}(x), I_{A}(x), F_{A}(x): U \rightarrow P([\psi, 1])$ w here $\psi<0<1$, and $\psi$ is called under limit. 
$T_{A}(x), I_{A}(x), F_{A}(x) \subseteq[\psi, 1]$, and $P([\psi, 1])$ is the set of all subsets of $[\psi, 1]$.An interval valued neutrosophic overset $\mathrm{A}_{2}$ is defined as $\mathrm{A}_{2}=\left\{\mathrm{x},<\mathrm{T}_{A}(x) ; I_{A}(x) ; F_{A}(x)>\mathrm{x} \in U\right\}$ such that in the neutrosophic component contains there is atleast one is partially or totally below 0 and no element has partially or totally above 1 .

\section{Definition 2.9 [27]}

Let $\mathrm{U}$ be the universe of discourse. A neutrosophic set $\mathrm{A}_{3}$ in $\mathrm{U}$ which consist the membership function $\mathrm{T}(\mathrm{x}), \mathrm{I}(\mathrm{x}), \mathrm{F}(\mathrm{x})$ that define true, indeterminacy and falsity respectively, of a generic element $x \in U$,

$$
T_{A}(x), I_{A}(x), F_{A}(x): U \rightarrow P[\psi, \varphi] \text { where } \psi<0<1<\varphi \text {, and } \psi \text { is called under limit while } \varphi \text { is called over }
$$
limit, $T_{A}(x), I_{A}(x), F_{A}(x) \subseteq P[\psi, \varphi]$ and $P[\psi, \varphi]$ is the set of all subsets of $[\psi, \varphi]$ An interval valued neutrosophic offset $\mathrm{A}_{3}$ is defined as $\mathrm{A}_{3}=\left\{\mathrm{x},\left\langle\mathrm{T}_{A}(x) ; I_{A}(x) ; F_{A}(x)>\mathrm{x} \in U\right\}\right.$ such that in the neutrosophic components contains atleast one is partially or totally above 1 and atleast another is partially or totally below 0 .

\section{Definition: 2.10 [17]}

Let $\mathrm{A}, \mathrm{B} \in \operatorname{IVNRS}(U)$.Then

1.Hamming distance between $\mathrm{A}$ and $\mathrm{B}$ is denoted as $\mathrm{d}_{\mathrm{H}}(\mathrm{A}, \mathrm{B})$ and is defined by

$$
\begin{aligned}
d_{H}(A, B)=\frac{1}{6} \sum_{j=1}^{P} & \sum_{i=1}^{n}\left(\left|T_{A}^{L}\left(x_{i}\right)-T_{B}^{L}\left(x_{i}\right)\right|+\left|T_{A}^{U}\left(x_{i}\right)-T_{B}^{U}\left(x_{i}\right)\right|+\left|I_{A}^{L}\left(x_{i}\right)-I_{B}^{L}\left(x_{i}\right)\right|+\left|I_{A}^{U}\left(x_{i}\right)-I_{B}^{U}\left(x_{i}\right)\right|\right. \\
& +\left|F_{A}^{L}\left(x_{i}\right)-F_{B}^{L}\left(x_{i}\right)\right|+\left|F_{A}^{U}\left(x_{i}\right)-F_{B}^{U}\left(x_{i}\right)\right|
\end{aligned}
$$

2.Normalized hamming distance between $A$ and $B$ is denoted as $\mathrm{d}_{\mathrm{NH}}(\mathrm{A}, \mathrm{B})$ and is defined by

$$
\begin{aligned}
d_{H}(A, B)=\frac{1}{6 n P} & \sum_{j=1}^{P} \sum_{i=1}^{n}\left(\left|T_{A}^{L}\left(x_{i}\right)-T_{B}^{L}\left(x_{i}\right)\right|+\left|T_{A}^{U}\left(x_{i}\right)-T_{B}^{U}\left(x_{i}\right)\right|+\left|I_{A}^{L}\left(x_{i}\right)-I_{B}^{L}\left(x_{i}\right)\right|+\left|I_{A}^{U}\left(x_{i}\right)-I_{B}^{U}\left(x_{i}\right)\right|\right. \\
& +\left|F_{A}^{L}\left(x_{i}\right)-F_{B}^{L}\left(x_{i}\right)\right|+\left|F_{A}^{U}\left(x_{i}\right)-F_{B}^{U}\left(x_{i}\right)\right|
\end{aligned}
$$

3.Euclidean distance between $A$ and $B$ is denoted as $d_{E}(A, B)$ and is defined by

$$
\begin{aligned}
d_{E}(A, B)=\frac{1}{6} \sum_{j=1}^{P} & \sum_{i=1}^{n}\left\{\left(\left|T_{A}^{L}\left(x_{i}\right)-T_{B}^{L}\left(x_{i}\right)\right|^{2}+\left|T_{A}^{U}\left(x_{i}\right)-T_{B}^{U}\left(x_{i}\right)\right|^{2}+\left|I_{A}^{L}\left(x_{i}\right)-I_{B}^{L}\left(x_{i}\right)\right|^{2}+\left|I_{A}^{U}\left(x_{i}\right)-I_{B}^{U}\left(x_{i}\right)\right|^{2}\right.\right. \\
& \left.\left.+\left|F_{A}^{L}\left(x_{i}\right)-F_{B}^{L}\left(x_{i}\right)\right|^{2}+\left|F_{A}^{U}\left(x_{i}\right)-F_{B}^{U}\left(x_{i}\right)\right|^{2}\right)\right\}^{\frac{1}{2}}
\end{aligned}
$$

4.Normalized Euclidean distance between $\mathrm{A}$ and $\mathrm{B}$ is denoted as $\mathrm{d}_{\mathrm{NE}}(\mathrm{A}, \mathrm{B})$ and is defined $d_{E}(A, B)=$ $\frac{1}{6 n P} \sum_{j=1}^{P} \sum_{i=1}^{n}\left\{\left(\left|T_{A}^{L}\left(x_{i}\right)-T_{B}^{L}\left(x_{i}\right)\right|^{2}+\left|T_{A}^{U}\left(x_{i}\right)-T_{B}^{U}\left(x_{i}\right)\right|^{2}+\left|I_{A}^{L}\left(x_{i}\right)-I_{B}^{L}\left(x_{i}\right)\right|^{2}+\left|I_{A}^{U}\left(x_{i}\right)-I_{B}^{U}\left(x_{i}\right)\right|^{2}+\mid F_{A}^{L}\left(x_{i}\right)-\right.\right.$ $\left.\left.\left.F_{B}^{L}\left(x_{i}\right)\right|^{2}+\left|F_{A}^{U}\left(x_{i}\right)-F_{B}^{U}\left(x_{i}\right)\right|^{2}\right)\right\}^{\frac{1}{2}}$

\section{Saturated Refined Neutrosophic sets}

Irfan Deli et al [28] presented the properties and various operations of neutrosophic refined sets. An element of neutrosophic refined set has a sequence of truth, indeterminacy and falsity membership values. In the model 
proposed by Irfan Deli et al [28] the symptoms of the patients at three different intervals of time are presented as neutrosophic refined sets. But in reality if the patients are undergoing treatment and the symptoms are checked at different intervals of time, suppose if a patient gets cured and gets back to normal conditions, then the symptoms of the disease are nil and it takes same values if testing of symptoms takes place at consecutive period of time. At this junction the membership values gets saturated, and this instance is the origin of saturated refined neutrosophic sets.

Let $\mathrm{U}$ be a universe of discourse. A neutrosophic saturated refined set (NSRS) A on U can be defined as follows

$$
\mathrm{A}=\left\{<\mathrm{x},\left(T_{A}^{1}(x), T_{A}^{2}(x) \ldots, T_{A}^{P}(x), T_{A}^{P}(x)\right),\left(I_{A}^{1}(x), I_{A}^{2}(x) \ldots I_{A}^{P}(x), I_{A}^{P}(x)\right),\left(F_{A}^{1}(x) F_{A}^{2}(x) \ldots F_{A}^{P}(x), F_{A}^{P}(x)>x \in\right.\right.
$$

$U$ and $0 \leq T_{A}^{i}(x)+I_{A}^{i}(x)+F_{A}^{i}(x) \leq 3,(i=1,2 \ldots P)$ and $T_{A}^{1}(x) \leq T_{A}^{2}(x) \leq \cdots \leq T_{A}^{P}(x)$ for any

$x \in A, T_{A}^{i}(x), I_{A}^{i}(x), F_{A}^{i}(x), i=1,2 \ldots P$ is the truth membership sequence, indeterminacy membership sequence and falsity membership sequence of the element $\mathrm{x}$ respectively.

Let $U$ be a universe of discourse. A interval - valued saturated refined neutrosophic set $A$ on $U$ can be defined as follows

$$
\begin{aligned}
& \mathrm{A}=\left\{<\mathrm{x},\left(\left[T_{A}^{L_{1}}(x), T_{A}^{U_{1}}(x)\right],\left[T_{A}^{L_{2}}(x), T_{A}^{U_{2}}(x)\right], \ldots . T_{A}^{p}(x)\right),\left(\left[I_{A}^{L_{1}}(x), I_{A}^{U_{1}}(x)\right],\left[I_{A}^{L_{2}}(x), I_{A}^{U_{2}}(x)\right], \ldots . I_{A}^{p}(x)\right),\right. \\
& \left(\left[F_{A}^{L_{1}}(x), F_{A}^{U_{1}}(x)\right],\left[F_{A}^{L_{2}}(x), F_{A}^{U_{2}}(x)\right], \ldots . F_{A}^{p}(x)\right)>x \in U \text { and } \quad 0 \leq T_{A}^{i}(x)+I_{A}^{i}(x)+F_{A}^{i}(x) \leq 3,(i= \\
& 1,2 \ldots P) \text { and } T_{A}^{1}(x) \leq T_{A}^{2}(x) \leq \cdots \leq T_{A}^{P}(x) \text { for any } \\
& x \in A, T_{A}^{i}(x), I_{A}^{i}(x), F_{A}^{i}(x), i=1,2 \ldots P \text { is the truth membership sequence, indeterminacy membership sequence and }
\end{aligned}
$$
falsity membership sequence of the element $x$ respectively.

\section{Remark:}

1. If any of the membership values is saturated it is partial in nature and it is also a saturated refined set.

2.The saturated refined neutrosophic sets can be extended to overset, underset and offset.

3.The interval - valued refined neutrosophic sets are also extended to saturated interval- valued refined neutrosophic sets and the saturated values varies from interval sets to single valued sets over a period of time.

\section{Application of the proposed decision making model}

A decision making model together with fuzzy relational matrix and saturated refined neutrosophic overset, underset and offset is validated with the following illustration.

\section{Decision Making Environment}

Presently COVID - 19 has brought a paradigm shift in teaching and learning process, the teaching fraternity is expected to possess digital teaching skills to face the post quarantine period. The developing nations have begun to encourage online educational system with the motive of unlocking learning during lock down. In this juncture the teachers are categorized based on their attributes and exposed to different kinds of training method to foster the acquisition of digital skills. The ultimate aim of this decision making model is to determine the suitable training method to the different kinds of teachers. This training programme is conducted to train the teachers to acquire online teaching skills. The expected outcome is enhancement of teacher's online teaching skills. The effectiveness of the programme is evaluated based on certain attributes and these attributes duly play crucial role in the enhancement of teacher's online teaching skills.

The attributes are 
A1 Trainer's efficiency- Refers to mastery

A2 Teacher's interest

A3 Teacher's duration of participation - present throughout the sessions

A4 Teacher's grasping ability - how quick they understand

A5 Trainer's Approach - Refers to inter personal relationship/ social skills

The teachers are made to undergo four phases of training namely I, II, III, IV and they are grouped into four categories and their characteristic features are presented in Table 4.1

Table 4.1 Types of Teachers \& Attributes

\begin{tabular}{|l|l|}
\hline $\begin{array}{c}\text { Types of } \\
\text { Teachers }\end{array}$ & \\
\hline T1 & Encouraging,Motivating,Systematic,Holistic \\
\hline T2 & Optimistic,creative,interactive,Facllitative \\
\hline T3 & Pragmatic,realistic,joyful,flexible \\
\hline T4 & $\begin{array}{l}\text { Weak commitment, Projective,Low professional ,Resistant to } \\
\text { change }\end{array}$ \\
& \\
\hline
\end{tabular}

The training to teachers are given using the following modes such as Self- paced learning, Blended learning, Adaptive learning, Virtual classes. The digital skills that are focussed in this training programme are Online skills, Digital literacy skills, Administrative skills of Learning Management System (LMS), Technology skills, Organization skills. The relation between digital skills and training methods are presented in Table 4.2

Table 4.2 Relation between skills and methods 


\begin{tabular}{|l|l|l|l|l|}
\hline & Blended Mode & Self- paced Mode & Adaptive Mode & Virtual Mode \\
\hline Online Skills & $([.45, .6],[0.2, .3],[$ & $([0.66, .8],[0.43, .5$ & $([0.63, .75],[0.49,$. & $([0.43, .58],[0.33,$. \\
& $0.39, .46])$ & $7],[0.2, .38])$ & $7],[0.3, .4])$ & $5],[0.61, .68])$ \\
\hline $\begin{array}{l}\text { Digital literacy } \\
\text { Skills }\end{array}$ & $([0.5, .61],[0.1, .39$ & $([0.43, .6],[0.15, .2$ & $([0.13, .31],[0.5, .7$ & $([0.3,39],[0.1, .43$ \\
& ]$,[.35,0.48])$ & $5],[0.38, .5])$ & $1],[0.44, .47])$ & ]$,[0.51, .62])$ \\
\hline $\begin{array}{l}\text { Administrative } \\
\text { skills of LMS }\end{array}$ & $([0.5, .65],[0.21, .4$ & $([0.45, .68],[0.2, .3$ & $([0.46, .62],[0.2, .3$ & $([0.65,, 78],[0.32,$. \\
\hline $\begin{array}{l}\text { Technology } \\
\text { Skills }\end{array}$ & $([0.4, .63],[0.1, .25$ & $([0.44, .5],[0.61, .6$ & $([0.27, .3],[0.53, .6$ & $(0.51, .59],[0.35,$. \\
& ], & $9]$, & ], & $4]$, \\
\hline $\begin{array}{l}\text { Organization } \\
\text { skills }\end{array}$ & $([0.69, .71])$ & $[0.25, .45])$ & $[0.39, .48])$ & $[0.23, .33])$ \\
& $9]$, & $([0.3, .65],[0.42, .5$ & $([0.33, .45],[0.45,$. & $([0.4, .53],[0.2, .35$ \\
& $[0.15, .2])$ & $2]$, & $5],[0.25, .3])$ & ]$,[0.13, .25])$ \\
\hline
\end{tabular}

The degree of acquisition rate of digital teaching skills is presented as saturated refined interval-valued neutrosophic overset, underset and offset in Table 4.3.

Table 4.3 Relation between Teachers and Skill acquisition

\begin{tabular}{|c|c|c|c|c|c|}
\hline & Online Skills & $\begin{array}{l}\text { Digital literacy } \\
\text { Skills }\end{array}$ & $\begin{array}{l}\text { Administrative } \\
\text { skills of LMS }\end{array}$ & Technology Skills & $\begin{array}{l}\text { Organization } \\
\text { skills }\end{array}$ \\
\hline T1 & $\begin{array}{l}([0.7,0.8],[0.3,0.4], \\
[0.5,0.7]) \\
([0.75,0.85],[0.41,0 . \\
5],[0.45,0.6]) \\
([0.79,0.95],[0.45,0 . \\
58], 0.4)\end{array}$ & $\begin{array}{l}{[(0.6,0.7],[0.2,0.3],} \\
[0.5,0.6]) \\
([0.65,0.75],[0.28,0 \\
.35],[0.43,0.48]) \\
([0.78,0.88],[0.36,0 \\
.4], 0.31) \\
([0.89,1.1],[0.37,0 . \\
41], 0.31)\end{array}$ & $\begin{array}{l}([0.5,0.6],[0.2,0.3],[ \\
0.1,0.3]) \\
([0.55,0.67],[0.31,0 . \\
43],[0.1,0.28]) \\
(0.61,[0.33,0.44],[.0 \\
.1,0.15]) \\
(0.61,[0.35,0.44],[- \\
.0 .1,0.12])\end{array}$ & $\begin{array}{l}([0.3,0.4],[0.7,0.8],[ \\
0.4,0.6]) \\
([0.37,0.45],[0.81,0 . \\
93],[0.52,0.58]) \\
([0.39,0.48], 1.3,[0.5 \\
3,0.56]) \\
([0.43,0.52], 1.3,[0.5 \\
4,0.55])\end{array}$ & $\begin{array}{l}([0.4,0.5],[0.2,0 . \\
3],[0.03,0.05]) \\
([0.46,0.57],[0.2 \\
6,0.35],[0.01,0.0 \\
3]) \\
(0.52,[0.28,0.37], \\
[0.01,0.02])\end{array}$ \\
\hline
\end{tabular}




\begin{tabular}{|c|c|c|c|c|c|}
\hline & $\begin{array}{l}([0.9,1.2],[0.48,0.59 \\
], 0.4)\end{array}$ & & & & $\begin{array}{l}([0.52,[0.31,0.38 \\
],[-0.01,0.01])\end{array}$ \\
\hline T2 & $\begin{array}{l}([0.6,0.7],[0.3,0.4],[ \\
0.7 .0 .8]) \\
([0.75,0.83],[0.33 .0 . \\
46],[0.71,0.75]) \\
([0.83,0.95],[0.4,0.4 \\
8], 0.68) \\
([0.96,1.3],[0.44,0.5 \\
4], 0.68)\end{array}$ & $\begin{array}{l}([0.5,0.6],[0.6,0.7], \\
[0.1,0.2]) \\
([0.56,0.61],[0.68,0 \\
.73],[0.1,0.15]) \\
([0.59,[0.71,0.75],[ \\
0.1,0.12]) \\
([0.59,[0.72,0.77],[ \\
-0.1,0.11])\end{array}$ & $\begin{array}{l}([0.4,0.5],[0.8,0.9],[ \\
0.3,0.4]) \\
([0.47 .0 .58],[0.88,0 . \\
97],[0.3,0.35]) \\
([0.55,0.63], 1.13,[0 . \\
3,0.34]) \\
([0.55,0.78], 1.13,[0 . \\
3,0.31])\end{array}$ & $\begin{array}{l}([0.7,0.8],[0.3,0.4],[ \\
0.2,0.3]) \\
([0.75,0.83][0.35,0 . \\
43],[0.1,0.2]) \\
([0.86,0.95], 0.39,[0 . \\
05,0.1) \\
([0.96,1.1], 0.39,[- \\
0.01,0.04])\end{array}$ & $\begin{array}{l}([0.3,0.4],[0.7,0 . \\
8],[0.5,0.6]) \\
([0.36,0.46],[0.7 \\
9,0.89],[0.5,0.55] \\
) \\
([0.37,0.53],[0.8 \\
9,0.99], 0.52) \\
([0.45,0.56],[0.9 \\
5,1.1], 0.52)\end{array}$ \\
\hline T3 & $\begin{array}{l}([0.8,0.9],[0.2,0.3],[ \\
0.4,0.5]) \\
([0.86,0.98],[0.3,0.4 \\
1],[0.4,0.45]) \\
(1.1,[0.38,0.49],[0.3 \\
5,0.4) \\
(1.1,[0.42 .0 .51],[0.3 \\
5,0.38])\end{array}$ & $\begin{array}{l}([0.4,0.5],[0.8,0.9], \\
[0.5,0.6]) \\
([0.47,0.57],[0.83,0 \\
.93],[0.45,0.57]) \\
([0.55,0.61], 1.2,[0 . \\
45,0.51]) \\
([0.55,0.62], 1.2,[0 . \\
45,0.49])\end{array}$ & $\begin{array}{l}([0.3,0.4],[0.2,0.3],[ \\
0.1,0.2]) \\
([0.38,0.47],[0.26,0 . \\
37],[0.1,0.15]) \\
(0.45,[0.28,0.39], \\
[0.1,0.12]) \\
(0.45,[0.28,0.42], \\
[-0.1,0.1])\end{array}$ & $\begin{array}{l}([0.5,0.6],[0.7,0.8],[ \\
0.3,0.4]) \\
([0.57,0.68],[0.85,0 . \\
91],[0.2,0.3]) \\
(0.63,[0.91,0.99],[0 . \\
2,0.25]) \\
(0.63,[0.98,1.2], \\
[0.21,0.23])\end{array}$ & $\begin{array}{l}([0.3,0.4],[0.4,0 . \\
5],[0.2,0.3]) \\
([0.35,0.46],[0.4 \\
7,0.57],[0.1,0.2]) \\
(0.43,0.52,[0.1,0 . \\
15]) \\
(0.43,0.52,[ \\
-0.1,0.12])\end{array}$ \\
\hline T4 & $\begin{array}{l}([0.3,0.4],[0.5,0.6],[ \\
0.2,0.3]) \\
([0.41,0.49],[0.6 .0 .6 \\
7],[0.1,0.2]) \\
([0.45,0.53], 0.61,[0 . \\
1,0.15]) \\
([0.45,0.55], 0.61,\end{array}$ & $\begin{array}{l}([0.5,0.6],[0.8,0.9], \\
[0.6,0.7]) \\
([0.52,0.61],[0.88,0 \\
.98],[0.5,0.6]) \\
([0.63,0.64], 1.3,[0 . \\
5,0.55])\end{array}$ & $\begin{array}{l}([0.7,0.8],[0.5,0.6],[ \\
0.36,0.57]) \\
([0.8,0.91],[0.55,0.6 \\
5],[0.36,0.55]) \\
([0.88,0.99], 0.61,[0 . \\
2,0.25])\end{array}$ & $\begin{array}{l}([0.2,0.3],[0.1,0.27] \\
[0.1,0.2]) \\
([0.4,0.63],[0.1,0.25 \\
],[0.1,0.13]) \\
([0.46,0.63], 0.26,[0 . \\
05,0.1])\end{array}$ & $\begin{array}{l}([0.3,0.4],[0.8,0 . \\
9],[0.5,0.6]) \\
([0.45,0.53],[0.8 \\
8,0.91],[0.45,0.5] \\
) \\
(0.45,[0.98,1.1], 0 \\
.41)\end{array}$ \\
\hline
\end{tabular}




\begin{tabular}{|l|l|l|l|l|l|}
\hline$[-0.1,0.11])$ & $([0.65,0.71], 1.3,[0$. & $([0.98,1.1], 0.61,[0.2$ & $([0.47,0.63], 0.26,[$ & $(0.45,[0.99,1.2], 0$ \\
$48,0.52])$ & $, 0.23])$ & & $-0.05,0.05])$ & $.41)$ \\
\hline
\end{tabular}

The normalized Hamming distance is used to determine the most suitable training method to teachers and the values are presented in Table 4.4 .

Table 4.4 Normalized Hamming Distance between Teachers and Methods

\begin{tabular}{|l|l|l|l|l|}
\hline & Blended Mode & Self- paced Mode & Adaptive Mode & Virtual Mode \\
\hline T1 & 0.214 & $\mathbf{0 . 1 8 3}$ & 0.194 & 0.217 \\
\hline T2 & 0.286 & 0.299 & 0.28 & $\mathbf{0 . 2 7 9}$ \\
\hline T3 & 0.245 & 0.199 & $\mathbf{0 . 1 8 5}$ & 0.246 \\
\hline T4 & & & & 0.27 \\
\hline
\end{tabular}

The results obtained by Hamming distance, Euclidean and Normalized Euclidean distance methods are presented in Table 4.5,4.6 and 4.7 respectively

Table 4.5 Hamming Distance between Teachers and Methods

\begin{tabular}{|l|l|l|l|l|}
\hline & Blended Mode & Self-paced Mode & Adaptive Mode & Virtual Mode \\
\hline T1 & 0.858 & $\mathbf{0 . 7 3}$ & 0.774 & 0.866 \\
\hline T2 & 1.142 & 1.174 & 1.122 & $\mathbf{1 . 1 1 7}$ \\
\hline T3 & 0.999 & 0.798 & $\mathbf{0 . 7 4 1}$ & 0.986 \\
\hline T4 & & 1.143 & 1.037 & 1.076 \\
\hline
\end{tabular}

Table 4.6 Euclidean Distance between Teachers and Methods

\begin{tabular}{|l|l|l|l|l|}
\hline & Blended Mode & Self-paced Mode & Adaptive Mode & Virtual Mode \\
\hline T1 & 0.115 & $\mathbf{0 . 0 9 5}$ & 0.096 & 0.12 \\
\hline T2 & 0.129 & 0.13 & 0.128 & $\mathbf{0 . 1 2 7}$ \\
\hline T3 & 0.131 & 0.112 & $\mathbf{0 . 0 8 7 6}$ & 0.124 \\
\hline
\end{tabular}




\begin{tabular}{|l|l|l|l|l|}
\hline T4 & $\mathbf{0 . 1 2 9}$ & 0.132 & 0.131 & 0.133 \\
\hline
\end{tabular}

Table 4.7 Normalized Euclidean Distance between Teachers and Methods

\begin{tabular}{|l|l|l|l|l|}
\hline & Blended Mode & Self-paced Mode & Adaptive Mode & Virtual Mode \\
\hline T1 & 0.0289 & $\mathbf{0 . 0 2 3 9}$ & 0.024 & 0.0274 \\
\hline T2 & 0.0321 & 0.0325 & 0.0323 & $\mathbf{0 . 0 3 1 7}$ \\
\hline T3 & 0.0328 & 0.028 & $\mathbf{0 . 0 2 1 9}$ & 0.031 \\
\hline T4 & & 0.033 & 0.0324 & 0.0332 \\
\hline
\end{tabular}

\section{Discussion}

Table 4.4,4.5,4.6 \&4.7 clearly presents the most suitable training method to various kinds of teachers. The lowest distance gives the apt method. Self- paced mode is suitable to type I teachers; Virtual mode to type II teachers; Adaptative mode to type III teachers and blended mode to type IV teachers. This optimal relation between teachers and methods are highly pragmatic as it has incorporated the influence of external and internal factors of the training programme. The various methods of distance measures are used to determine the feasible method of teaching and on comparative analysis, the results obtained by using the different methods, are same. The proposed decision making model with saturated refined neutrosophic sets of different kinds can be extended further with other representations of neutrosophic sets, also other kinds of distance measures can be applied to find the optimal method of teaching. This model also has certain limitations as neutrosophic oversets, undersets and offsets of representations are used only specifically and these special kinds of representations cannot be applied at all circumstances. This decision -making model caters to particular needs.

\section{Conclusion}

In this research work the concept of saturated refined neutrosophic sets, interval -valued saturated refined neutrosophic sets and its extension to neutrosophic overset, underset and offset are proposed. A decision making model with fuzzy relational matrix and saturated refined neutrosophic overset, underset and offset is proposed in this paper. The model is validated with a real life application. This research work will certainly enlighten the researchers to explore in deep about the concepts of neutrosophic overset, underset and offset. The profound extension of these concepts will disclose new portals of neutrosophic research.

\section{References}

[1] Zadeh,L.A., “Fuzzy sets”, Information and Control, vol. 8, pp. 338-353, 1965.

[2] Atanassov,K.T., "Intuitionistic fuzzy sets”, Fuzzy sets system, vol. 20, pp.87-96,1983. 
[3] Khan .,Saleem Abdullah., “ Interval-valued Pythagorean fuzzy GRA method for multipleattribute decision making with incomplete weight information", International journal of Intelligent systems, Vol.33, pp .1689-1716, 2018.

[4] Zhuosheng Jia,Yingjun Zhang., "Interval valued Intuitionistic fuzzy multiple attribute group decision making with uncertain weights”, Mathematical Problems in Engineering, Special Issue, pp 1-9,2019.

[5] Smarandache,F., "Neutrosophic set, a generalization of the Intuitionistic Fuzzy Sets", International Journal of Pure and Applied Mathematics, vol 24, pp.287-297, 2005.

[6] Abdel-Baset, M., Chang, V., \& Gamal, A., "Evaluation of the green supply chain management practices: A novel neutrosophic approach" Computers in Industry, vol.108, pp. 210-220, 2019.

[7] Abdel-Baset, M., Chang, V., Gamal, A., \&Smarandache, F., "An integrated neutrosophic ANP and VIKOR method for achieving sustainable supplier selection: A case study in importing field", Computers in Industry, vol.106, pp.94-110,2019.

[8] Hu.J,Pan.L, and Chen.X, "An interval neutrosophic projection-based VIKOR method for selecting doctors". Cognitive Computation, vol.9, pp.801-816,2017.

[9] Nada A., Nabeeh, Ahmed Abdel-Monem and Ahmed Abdelmouty., "A Hybrid Approach of Neutrosophic with MULTIMOORA in Application of Personnel Selection", Neutrosophic Sets and Systems, vol. 30, pp. 1-21,2019.

[10] Ajay, D., Aldring, J., Abirami, S., and Martina, D. J. S., “A SVTrN-number approach of multi-objective optimisation on the basis of simple ratio analysis based on MCDM method”, International Journal of Neutrosophic Science, vol .5, pp.16-28, 2020

[11] Sahidul Islam and Sayan Chandra Deb., "Neutrosophic Goal Programming Approach to A Green Supplier Selection Model with Quantity Discount”, Neutrosophic Sets and Systems, vol. 30, pp. 98-112,2019.

[12] Mullai,M., Broumi, S., Surya,R., and Madhan Kumar,G., “ Neutrosophic Intelligent Energy Efficient Routing for Wireless ad-hoc Network Based on Multi-criteria Decision Making", Neutrosophic Sets and Systems, vol. 30,pp. 113-121,2019.

[13] Abdel Nasser H, Zaied., Abduallah Gamal, Mahmoud Ismail., “An Integrated Neutrosophic and TOPSIS for Evaluating Airline Service Quality”, Neutrosophic Sets and Systems, vol. 29, pp. 30-39, 2019. 
[14] Muhammad Saqlain, Muhammad Saeed, Muhammad Rayees Ahmad, Smarandache,F., "Generalization of TOPSIS for Neutrosophic Hypersoft set using Accuracy Function and its Application”, Neutrosophic Sets and Systems, vol. 27, pp. 131-137, 2019.

[15] Surapati Pramanik, Partha Pratim Dey., "Multi-level linear programming problem with neutrosophic numbers: A goal programming strategy", Neutrosophic Sets and Systems, vol. 29, pp. 242-254, 2019.

[16] Ajay, D., \& Aldring, J., “ A Decision Making Technique Based on Similarity Measure and Entropy of Bipolar Neutrosophic Sets".The International journal of analytical and experimental modal analysis, vol. 1, pp.520-529, 2019.

[17] Ajay, D., Broumi, S., \& Aldring, J., “An MCDM Method under Neutrosophic Cubic Fuzzy Sets with Geometric Bonferroni Mean Operator", Neutrosophic Sets and Systems, vol-32, pp.187, 2020.

[18] Chakraborty A, Mondal, Alam, Mahata, "Cylindrical Neutrosophic Single-Valued Numberand its Application in Networking problem, Multi Criterion Decision Making Problem and Graph Theory",2020 CAAI Transactions on Intelligence Technology; DOI: $10.1049 /$ trit.2019.0083.

[19] Chakraborty.A, Banik.B, Mondal and Alam, "Arithmetic and Geometric Operators of Pentagonal Neutrosophic Number and its Application in Mobile Communication Based MCGDM Problem”, Vol 32, 2020.DOI: 10.5281/zenodo.3723145.

[20] Deli, I., \& Şubaş, Y., “ Some weighted geometric operators with SVTrN-numbers and their application to multi-criteria decision making problems" Journal of Intelligent \& Fuzzy Systems, vol.32, pp.291-301, 2017.

[21] Deli, I., \& ozturk, E. K., “ Two Centroid Point for SVTN-Numbers and SVTrN-Numbers: SVN-MADM Method”, In Neutrosophic Graph Theory and Algorithms , pp. 279-307, pp.279-307, 2020.

[22] Juanjuan ding, Wenhui Bai,Chao Zhang., "A New Multi-Attribute Decision Making Method with single-valued Neutrosophic Graphs", International journal of neutrosophic science ,vol.11 ,pp.76-86, 2020.

[23] Dragisa stanujkic,Darjan Karabasevic,Florentin Smarandache,Gabrijela Popovic., “A novel Approach for assessing the Reliability of Data Contained in a single valued 
Neutrosophic number and its application in multiple criteria decision making", International journal of neutrosophic science, vol.11, pp.22-29, 2020.

[24] Shahzaib Ashraf, Saleem Abdullah., "Decision Support Modeling for agriculture land selection based on sine trigonometric single valued neutrosophic information", International journal of Neutrosophic Science, vol.9, pp.60-73, 2020.

[25] Muhammad Naveed Jafar, Mushal Zia, Ayisha Saeed, Maryam Yaqoob, samreen habib, "Aggregation Operators of Bipolar Neutrosophic Soft Sets and It's Applications In Auto Car Selection”, International journal of Neutrosophic Science, vol-9, pp.37-46, 2020.

[26] Philippe Schweizer, "Thinking on Thinking: The Elementary forms of Mental Life Neutrosophical representation as enabling cognitive heuristics", International Journal of Neutrosophic Science, vol 2 , pp.63-71,2020.

[27] Florentin Smarandache, "Operators on single valued neutrosophic oversets, neutrosophic undersets and neutrosophic off sets", Journal of Mathematics and Informatics, vol-5, pp.6367, 2016.

[28] Irfan Deli., Said Broumi., Florentin Smarandache, “ On neutrosophic refined sets and their applications in medical diagnosis", Journal of New Theory,vol. 6, pp.88-98, 2015.

[29] Said Broumi and Irfan Deli., "Correlation measure for neutrosophic refined sets and its application in medical diagnosis", Palestine Journal of Mathematics, vol 5, pp.135-143, 2016. 